\title{
Hip Joint Osteoarthritis Pain Sources and Control
}

\author{
Ray Marks \\ Department of Health and Behavior Studies, Teachers College, Columbia University, New York, USA \\ Email:rm226@columbia.edu
}

How to cite this paper: Marks, R. (2020) Hip Joint Osteoarthritis Pain Sources and Control. Pain Studies and Treatment, 8 , $1-21$.

https://doi.org/10.4236/pst.2020.81001

Received: January 6, 2020

Accepted: January 28, 2020

Published: January 31, 2020

Copyright (C) 2020 by author(s) and Scientific Research Publishing Inc. This work is licensed under the Creative Commons Attribution International License (CC BY 4.0).

http://creativecommons.org/licenses/by/4.0/

\section{(c) (i) Open Access}

\begin{abstract}
Hip joint osteoarthritis, a widespread disabling disease with no known cause, produces considerable bouts of intractable pain as a result of multiple disease associated problems. This paper examines some sources of osteoarthritic hip joint pain, a poorly understood topic at best. Presented in three parts are data retrieved from several sources, including animal models. It is concluded that to improve the effectiveness of treatments designed to minimize hip osteoarthritis pain, a better understanding of the diverse origins of hip joint pain, and hip joint neurology, may permit the development of more precise as well as targeted pain strategies.
\end{abstract}

\section{Keywords}

Hip Joint, Innervation, Muscles, Nerves, Osteoarthritis, Pain, Prevention, Treatment

\section{Introduction}

The hip, a ball and socket joint of the synovial type serving a prominent weight-bearing function is quite commonly affected by osteoarthritis, a progressively disabling musculoskeletal condition, culminating from traumatic hip injuries, metabolic hip conditions, and vascular problems, among other causes. A degenerative disease that commonly produces high levels of intractable pain, stiffness, and movement dysfunction, hip osteoarthritis, which involves the articular cartilage lining of the joint, plus surrounding tissues, including the synovial membrane lining the joint capsule, muscles, ligaments, tendons, and bone, is not always amenable to or remediated by surgery or invasive strategies. Pharmacologic pain treatments are similarly often ineffective in relieving pain [1], limited in terms of reversing or attenuating the disease, and can be more harmful than not in some cases [2]. As such, efforts to uncover or clarify the key 
sources of hip joint osteoarthritis pain, especially those of neurogenic origin appear of high import especially when considering global aging, and data showing a high anticipated prevalence of the disease worldwide in the next few decades. In this regard, a careful review of the neural structures serving the hip joint, as well as their functional roles, and other neural factors, may be useful for advancing a better understanding of the possible sources of osteoarthritic hip joint pain, as this pertains to its safe and effective amelioration or remediation.

Indeed, while often viewed as a progressive irreversible age-associated biomechanical disorder, understanding the specific role of the neural sources of painful degenerative joint changes at the hip joint may not only be helpful in efforts to prevent excess pain or its onset and possible manifestations, but also for delineating the possible sources of prevailing pain with greater accuracy than not, and that may actually induce further pain and joint destruction if these remain poorly treated or untreated. Oo the contrary if the sources of osteoarthritis hip joint pain can be accurately delineated, ensuing treatments designed to target these determinants are more likely to be advantageous, regardless of approach.

In this respect, research shows that in keeping with its mobility and weight-bearing functions, the hip, a multiaxial synovial joint of the ball-and-socket type derived from the L2-S1 segments of the mesoderm is well-endowed with nerves arising from these segments [3] [4].

In addition, in accordance with Hilton's law, the trunk of the nerve to the hip joint whose branches supply muscles moving the joint also provides articular contributions to the joint [5], as do accessory articular nerves derived from the muscles related to the hip joint [6]. Hence, the sources of pain at the hip are likely to be diverse in origin, and may stem from spinal or muscle abnormalities, or both, in addition to joint damage and inflammatory processes that can affect the sensitivity of the hip joint to noxious as well as non-noxious stimuli independently or collectively [7]. These factors and others such as delayed reflex responsiveness may also be implicated in pain production if postural control at the affected hip joint is adversely affected due to mechanoreceptor sensory transmission deficits [8]. The hip joint nerves may also undergo independent or collective physiological and anatomical changes associated with the onset of osteoarthritis that can impact the expression of hip joint pain and its negative functional impacts [9].

\section{Review Aims}

This review aimed to a) examine and describe the most likely sources of hip osteoarthritis pain; b) highlight some methods for ameliorating hip osteoarthritis pain by applying this knowledge.

\subsection{Rationale}

The rationale for reviewing this topical material, which focuses predominantly on the neurology of the hip joint was the underlying belief that more emphasis 
on acknowledging the highly diverse and extensive array of neural sources that might underpin hip joint osteoarthritis pain might prove more efficacious than not in the long run, to both the clinician and surgeon, than simply applying standard forms of intervention that do not clearly take into account the importance of the hip joint mechanoreceptors, plus the anatomical and nociceptive complexity of the nerve supply at the hip [10] and other factors [11] that may impact neural pain transmission such as inflammatory factors.

\subsection{Significance and Organizing Framework}

It was hoped this review would provide insight into the problems of pain and movement disturbances which characterize the osteoarthritic hip joint as this applies to the implementation of insightful preventive, as well as rehabilitation strategies to limit or ameliorate this widespread disability.

This paper is a narrative one divided into three major components, including the implications of this information for research and practice. It houses articles extracted largely from PUBMED

[https://www.ncbi.nlm.nih.gov/pubmed/20428398] published between January 1 1980-March 5, 2020 using the keywords: hip joint innervation, hip joint innervation and pain, hip joint osteoarthritis pain mechanisms, and treatment. To this end, the entire list of entries was initially reviewed and only salient articles and those meeting the review inclusion criteria of a focus on hip osteoarthritis pain origins or treatment approaches were carefully reviewed by the author for their observations, regardless of research mode. The reviewed material was not quantified systematically, but was organized into those articles that discussed neuronal pathways of pain located in the periphery rather than on cognitive or psychosocial pain correlates, while the discussion centers on conservative forms of intervention, rather than surgical and invasive approaches for ameliorating hip osteoarthritis pain. The data selected and keywords chosen were those deemed by the author to encompass the most salient body of knowledge on this current topic, while excluding data related to surgical interventions. To ensure the data were inclusive of the state of the literature, additional manual searches and searches of other databases were undertaken to locate additional papers. Some data previously collected in our laboratory were also examined.

\section{Search Results}

The keywords used in PUBMED yielded 515 citations for Hip Joint Innervation; 145 citations for Hip Joint Innervation and Pain; 108 citations for Hip Joint Osteoarthritis Pain Mechanisms, and 73 for Treatment related facts. These data were scrutinized and were included in this report if they discussed or alluded to any of the topics listed below.

\subsection{Basic Hip Joint Neuroanatomy}

The background literature on this topic reveals that the basic nerve supply of the hip joint, initially studied in the mid-1800s by several anatomists such as Cru- 
veilhier (1844); Rudinger (1857); and Duzea (1886) [12] is extensive, but not always uniform. Commonly arising from the L1-S1 spinal segmental levels, the hip joint is served specifically by branches of the femoral, obturator, sciatic, and inferior gluteal nerves related to these segments. While rarely implicated simultaneously in painful hip joint osteoarthritis, early as well as later studies showed the hip joint primary nerves supplying the hip joint to also supply the overlying muscles [12]. Other nerves supplying the hip joint were found to include the superior gluteal nerve [12], the nerve to the quadratus femoris muscle, and on occasion an accessory obturator nerve [13]. Sympathetic fibers from lumbar ganglia reaching the joint via the articular vessels were described as well.

In terms of structures in the hip joint supplied by the nerves listed above, some were found to ramify in the fibrous layer of the hip joint capsule [14] [15], while others tended to branch out to accompany blood vessels, some extended into the synovial tissue and neighboring portions of the femur including the periostial tissue covering the hip bone.

These innervations patterns were clearly quite inconsistent though in distribution or mode of branching [3] [6] [12]. Gerhardt et al. [16] for example, concluded that the acetabular labrum, as well as the capsule of the human hip joint and the transverse acetabular ligament are very densely innervated, but that the anterior zone of the labrum was seen to be supplied by the highest concentration of Ruffini type nerve endings, which subserve motion and position sense, and are sensitive to stretch. Accordingly, their over- or understimulation as a result of disease or trauma may be associated with hip joint pain production, as may capsular and ligamentous damage. Shirai et al. [17] also found immunoreactive sensory fibres in the labrum and synovium situated in the weight bearing portion of the osteoarthritic hip thought to produce pain or be involved in pain production in the pathogenesis of osteoarthritic hip joint pain, implying an important possible role for joint structural nerves in the context of movement control as well as inflammation.

In another study, Haversath et al. [18] who examined histological capsular samples in patients with hip pain found pain-associated free nerve ending that were located predominantly at its base, but that these decreased in density towards the periphery. The hip capsule however, had evidence of nociceptive and pain-related fibres in all investigated areas, which could indicate why pain at the hip can be readily evoked, regardless of movement direction. Kilicarslan et al. [19] also noted abundant free nerve fibres in the transverse acetabular ligament and labrum in specimens from osteoarthritis hip patients. Cases with hip arthrosis may however have lower numbers of mechanoreceptors and free nerve endings than those without arthrosis [20], although the implication of this finding was not discussed.

It has also been shown that the nerve to the ligamentum capitus femoris-a component of the hip joint-may be involved in mediating pain [21]. Lying close to articular blood vessels, it also sends a few twigs to the acetabular fat pad in the cotyloid notch [12] that may also serve as a pain generating site. 
In a very interesting study by Saxler et al. [22], the authors found the presence of the tachykinen receptor neurokinen 1 localized in the walls of venous vessels, nerve fibres and Schwann cells of nerve bundles of the hip joint capsule specimens of three hip osteoarthritis patients, and that these were enhanced, rather than reduced. These receptors play a role in influencing pain production by substance $\mathrm{P}$, a peptide secreted by neurons that can provoke pain and inflammation, and that may explain the extent of suffering in hip osteoarthritis, especially during weightbearing.

Genth et al. [23] further observed that there was a small sensory nerve supply to the periosteum and bursae of the greater trochanter of the hip joint, and that this was a branch of the femoral nerve that accompanied arteria and vena circumflexa femoris medialis and their trochanteric branches to the greater trochanter, and that could account for the aching and bone pain often experienced in the disease. In their study, Rabinowicz and Jacqueline [24] also found small capsular and synovial nerves mainly located close to blood vessels, and that these were modified in the presence of inflammatory and mechanical disturbances, that could probably lead to severe pain.

In sum, a broad array of primary nerves derived from the lumbosacral spine supply the hip joint via the muscles, or directly through a highly diverse articular network. Very closely aligned with the vascular supply, the articular nerves themselves are highly diverse, not regularly dispersed, and are constituted by four distinct types of neural end organs that appear to have differential structures and functional roles as outlined below.

\subsubsection{Type I Nerve Endings}

The type I nerve endings, also termed Ruffini nerve endings are small, globular, encapsulated end-organs located mainly in the superficial layers of the hip joint capsule. They respond readily to low order stimuli, and fire for prolonged periods in response to changing patterns of stress in the joint capsule [12]. Their fluctuating discharges reflexively affect muscle tone, both at rest and during movement, as well as playing a role in the perceptual awareness of joint position and joint movement [16]. They thus play an important role in coordinating muscular control [12] [16], and as such can directly or indirectly influence the production and extent of any prevailing pain.

\subsubsection{Type II Nerve Endings}

These endings, also termed Pacinian endings, are seen less frequently in the hip joint, where they cluster mainly in the deep layers of the capsule [12]. They function as low threshold, rapidly-adapting mechanoreceptors that are inactive when the joint is at rest, but fire in response to altered stresses in the joint capsule or ligaments with a brief burst of impulses that last for only half a second or less and which provokes transient reflex adjustments in muscle tone. The type II receptors do not contribute to perceptual awareness of joint position, but their actions can clearly reproduce pain or render the joint susceptible to injury if abnormal in any way [16]. 


\subsubsection{Type III Nerve Endings}

These Golgi-type end organs are confined to the ligaments and behave as high threshold, slowly-adapting mechanoreceptors. They are inactive at rest and remain so during moderate degrees of joint displacement. They reflexively inhibit the tone of prime movers when they are activated at the extremes of joint movement [12], but if they are overstretched, or fail, the joint may be vulnerable to injury and pain.

\subsubsection{Type IV Nerve Endings}

Type IV free nerve endings constituted by Adelta and C fibres are sensory fibres that serve to detect and relay noxious joint stimuli to the central nervous system [16]. While they do not fire unless stimulated, these nerve receptors may become sensitive to innocuous as well as noxious mechanical, chemical, or thermal stimuli via high threshold mechanosensitive ion channels [25]. They may be found in the capsule, ligaments, and the inner lining of blood vessels [12] [26].

Taken together, these nerve endings and their afferent fibers described above are responsible first for the provision of articular sensation, and secondly, for the generation of reflexes that govern the activity of the related striated musculature [26]. As well, type IV receptors communicate with the central nervous system and may be responsive to both mechanical as well as inflammatory stimuli [27]. In a very interesting study, Kapetanakis et al. [28] found cases with osteoarthritis to exhibit an apparent conversion of encapsulated mechanoreceptors to fine nerve endings in the pathologically associated acetabular labrum that may impact hip joint mechanics and pain and warrants further study. There may also be a decrease in relative numbers of Pacinian corpuscles in those with osteoarthritis that may impact their ability to react rapidly [20] that has unexplored clinical implications. Free nerve endings, plus sensory receptors present in the walls of blood vessels found in femoral head ligaments that may regulate blood vessel caliber may similarly be involved in osteoarthritis pain production, in addition to having sensory functions [29].

These varied disease associated changes in hip joint mechanoreceptor numbers and sensibility, can predictably be expected to not only impact pain production directly, but indirectly via their effects on muscle responses, and joint stability, among other factors as outlined below [12] [20] [26] [30].

\subsection{Osteoarthritic Hip Joint Pain}

\subsubsection{Sources}

As noted above, the topic of osteoarthritic hip joint pain is a complex one, where pain may originate both within and outside the joint [29] with no degree of consistency, given the whole joint, including muscles, bone, ligaments, and joint capsule may be subject to degenerative and inflammatory changes. As well, despite the fact that articular cartilage, the key involved tissue in osteoarthritis, is commonly cited as having no nerve supply [31], this tissue when damaged may yet produce pain via the transient receptor potential ankyrin 1 (TRPA1), a 
membrane-associated cation channel, widely expressed in neuronal cells and involved in nociception and neurogenic inflammation processes [32].

Pain expression in hip osteoarthritis is also expected to be non-uniform even if the same tissue is involved, and can occur in acute versus chronic forms, and as a result of central as well as peripheral influences or both [33]. In addition, hip joint pain in osteoarthritis cases may stem from the activation of sensory as well as sympathetic nerve fibers [34], alongside inflammatory or biomechanical influences or both, and may not only be localized to the hip, but can possibly extend as far as the knee joint or lower leg. Pain severity in this respect may possibly be more exaggerated in the obese or severely compromised patient with multiple affected joints, as well as the diabetic patient.

While the key sources of potentially modifiable contributors to hip osteoarthritis pain are multiple and can act independently or interactively as outlined in Table 1, hip osteoarthritis pain may be mediated or moderated by chemical changes affecting neuropeptides such as substance P [43] [44] linked to enzymes that destroy cartilage constituents [33] and that can lower the nociceptive threshold of pain transmitting fibers [44]. As well, the presence of any prevailing degeneration of the proprioceptive, kinesthetic and vasoregulatory nerves may

Table 1. Conceptualization of key sources of hip osteoarthritis pain likely to be interactive and potentially modifiable by conservative non-pharmacologic non-surgical approaches.

\begin{tabular}{|c|c|c|}
\hline Cognitive Factors & Behavioral Factors & Peripheral Factors \\
\hline Anger & Altered gait pattern & Access to care and resources \\
\hline Anxiety & High level high-impact activities & Bone damage \\
\hline Depression & Injury/joint overloading & Cartilage damage \\
\hline Fatigue & Occupational stresses & Comorbid health correlates \\
\hline Fear & Prolonged sitting or standing & Capsular damage \\
\hline Low self-efficacy & Repetitive movements & Foot wear issues \\
\hline Insomnia & $\begin{array}{l}\text { Spino-pelvic compensatory } \\
\text { movements }\end{array}$ & Muscle imbalance/spasm \\
\hline Pain catastrophizing & Trauma exposure & Leg length discrepancies \\
\hline High pain vigilance & Sleep deprivation & Inflammatory factors \\
\hline Negative beliefs & Sedentary lifestyle & Joint instability/malalignment \\
\hline Stress & Poor Weight Control & Limited endurance capacity \\
\hline \multirow{5}{*}{ Other: } & \multicolumn{2}{|c|}{ Muscle weakness/atrophy } \\
\hline & \multicolumn{2}{|c|}{ Nerve damage } \\
\hline & \multicolumn{2}{|c|}{ Obesity } \\
\hline & \multicolumn{2}{|c|}{ Proprioceptive deficits } \\
\hline & \multicolumn{2}{|c|}{ Vascular factors } \\
\hline
\end{tabular}

Adapted from: Buckland et al. [35], Calders et al. [36]; Egloff et al. [37], Hunter et al. [38], Malfait and Snitzer [39]; Marks [40]; Moraes et al. [20], Syx et al. [41], van Dijk et al. [42]. 
cause pain, as well as peripheral nerve and central nervous system sensitization to pain, that further amplifies prevailing inflammatory responses and their negative modulating and mediating pain associated actions [45] [46].

In addition to the abovementioned pain sources, additional pain in the region of the osteoarthritic hip joint may stem from the fat pads located in the hip joint socket area, the periosteum covering the hip bones, and especially from those structures located adjacent to a diseased hip joint, which are all densely innervated with pain receptors [47] [48] [49]. Pain may also be experienced by the hip osteoarthritis patient due to a variety of local immune responses [50] [51] [52], in addition to persistent progressive inflammatory processes [43], and altered muscle activation patterns, poorly timed muscle responses, and excess or aberrant joint motion [52] due to ligamentous damage [43] that may induce pain and foster its persistence. Pain may also arise as a result of physiological changes to the nerves themselves, as well as the reactivity of nerves that produce painful stimuli [53] [54] [55] [56] [57], and associated vascular and bone derived pathological changes [19] [43] [58] [59] [60] [61] [62].

In this regard, Rabinowicz and Jacqueline [24] who examined an array of hip synovial membranes from hip osteoarthritis cases and others, found the small capsular and synovial nerves mainly located near blood vessels were indeed modified structurally, both focally as well as segmentally. Moreover, on occasion, the destruction involved demyelination processes and axon losses.

Unfortunately, one or more of these pain sources has the proclivity to foster nerve desensitization and prolonged firing in the diseased state [63], and a pain state that is often unchanged, despite hip joint replacement surgery [64]. This pain state may be quite diffuse in nature with certain areas of maximum intensity [65], while exhibiting features of neuropathic [66] as well as inflammatory pain [17] [51] [55] [67], along with episodes of ligamentous sprain with movement that provoke pain [6].

Other sources of hip osteoarthritis pain variations are deficient vitamin D levels [68], genetic polymorphisms [69], obesity [30] [70], and disturbances of circadian timekeeping [71].

\subsubsection{Distribution Patterns}

Given the many sources of neural inputs and outputs involved in hip physiology, hip disorder patients are said to typically experience a variety of local as well as referred pain patterns, plus varying pain descriptors, and intensity [54] [71], including muscle and joint pain. For example, according to the chart created by Wroblewski [72] to depict pain patterns in 89 patients with primary hip-joint contractures, findings clearly showed a heterogeneous pain distribution [see $\mathrm{Ta}$ ble 2].

In their study, Poulsen et al. [73] using a manikin approach found 77\% of 109 primary care cases with hip osteoarthritis reported pain located in the area of the greater trochanter, $53 \%$ reported pain in the groin area, $42 \%$ the anterior thigh, $38 \%$ the buttock area, $17 \%$ the knee, and 15\% the lower leg. Bhatia et al. [74] 
Table 2. Variations in hip joint pain patterns reported by Wroblewski [72].

\begin{tabular}{ccc}
\hline Pain Site & Numbers respondents & \% responding \\
\hline Greater trochanter & 71 & 80 \\
Medial buttock & 40 & 45 \\
Groin & 47 & 53 \\
Anterior thigh & 63 & 70 \\
Knee & 70 & 80 \\
Shin & 40 & 45 \\
\hline
\end{tabular}

reported meantime that pain related to hip joint osteoarthritis can occur in more than one location including the groin, gluteal areas, thigh, and possibly the area below the knee. In our own research, we identified highly diverse subjective pain descriptors when assessed in selected cases with unilateral end stage hip osteoarthritis [see Table 3].

In sum, contrary to a simplistic pain model where articular pain is generated when the type IV pain receptors in various joint structures such as the capsule and ligaments are irritated mechanically or chemically [16], many other structures may be implicated in various ways in sending pain messages to and from the spinal cord, and central nervous system. In particular, in addition to direct mechanical irritation of the fibrous capsule and ligaments of the joint that can deliver noxious afferent impulses to the cerebral cortex by way of the spinothalamic and spinoreticular tracts which subserve pain, pain can emanate from other sources, such as the vasculature, and a variety of inflammatory sources [17] [51], or both. The pain of hip osteoarthritis can also stem from multiple or single nerve impulses as a result of external or internal forms of nerve damage, lesions of the lumbar spine, the surrounding muscles, and capsular tissues, cartilage and bone sources. Pain may also occur as a result of the surgical removal of selected joint structures that place excess stress on remaining structures [16], an imbalance in mechanoreceptor inputs, or if disruption of the joint tissues alters the required feedback to the central nervous system responsible for maintaining joint stability [16].

The more recent findings of the possible activation of 3 types of glial cells in the development and maintenance of chronic pain activation via a number of synergistic neuro-glial interactions that have been shown to powerfully modulate excitatory and inhibitory synaptic transmission at presynaptic, postsynaptic, and extrasynaptic sites may also help to explain why pain is not easy to obviate [75]. The presence of an excess number of neurokinen 1 receptors in the walls of venous vessels, and on nerve fibers and Schwann cells found in the hip joints of patients with painful osteoarthritis may also provoke considerable degrees of excess pain according to the findings of Saxler et al. [54].

\subsection{Pain Control}

Since intense pain often prevents normal weight-bearing function in hip osteoarthritis, and this could undoubtedly exacerbate the extent of the condition 
Table 3. Sampling of pain descriptors reported at baseline among a representative sample of unilateral hip osteoarthritis surgical cases showing these vary widely by intensity, nature, and extent [Author].

\begin{tabular}{|c|}
\hline BURNING \\
\hline Burning pain: leg and hip \\
\hline Burning, aching, stabbing hip, knee, and leg pain \\
\hline CONSTANT \\
\hline Constant hip pain \\
\hline Constant hip pain with occasional burning sensation, and leg pain \\
\hline Constant stabbing pain of the affected hip \\
\hline MILD \\
\hline Mild aching thigh, groin, and knee \\
\hline Mild stabbing pain hip \\
\hline Mild, moderate to severe aching hip, groin, knee \\
\hline Mild aching pain in knee and lower leg \\
\hline MODERATE \\
\hline Moderate, aching pain hip \\
\hline Moderate aching in pelvic area \\
\hline Moderate to severe aching and burning \\
\hline Moderate stabbing pain hip \\
\hline Moderate ache in thigh, groin \\
\hline Moderate to severe aching hip, back leg, groin/knee/inner thigh \\
\hline Moderate pain in hip and back \\
\hline Pain in leg and knee \\
\hline Pain in hip and knee \\
\hline Pain at rest \\
\hline PINCHING \\
\hline Pinching sensation located in hip, thigh, and back \\
\hline SEVERE \\
\hline Severe groin and knee pain \\
\hline Severe aching knee \\
\hline Severe aching hip \\
\hline Severe stabbing pain in groin area \\
\hline Severe stabbing pain hip/groin/knee \\
\hline Severe burning, aching, hip and both legs/groin/knee \\
\hline Severe pain in both hips \\
\hline
\end{tabular}

[18], the primary aim of therapy in the management of hip joint osteoarthritis is to relieve pain, and thereafter, to normalize function. After a careful assessment 
and history taking, of high practical importance to the resolution of pain is the knowledge that excess or aberrant movements, as well as excess weight can exacerbate pain, as well as joint destruction. Thus simply trying to apply remedies that minimize inflammation or mask pain without attempts to modify weight bearing and optimize body weight forces, if problematic, is much more likely than not only to fail, and to be more harmful than not. Similarly, although direct stimulation of the various hip joint mechanoreceptors may be predicted to close the "gate" to nociceptive influences [26], this approach alone cannot suffice, if for example, hip joint stability and ligamentous constraints are compromised in some way, or balance capacity itself, is impaired. Another important point that is often overlooked in an effort to quell hip osteoarthritis pain, for example by recommending opioids, is that simply masking the pain, may not prevent pain from spreading to areas other than the hip joint, or any ensuing desensitization of the body to non-noxious stimuli. The spread of pain, plus the 'spread' of osteoarthritis to other joints, must also be considered as possible negative outcomes of suboptimal poorly conceived pain control as a result of the increased potential for joint microtrauma. Similarly, the "popular" use of radio frequency nerve ablation, denervation, or nerve blocks, or intra articular injections, while possibly relieving osteoarthritis hip joint pain, might actually produce a Charcot's or insensible joint situation whose use is then potentially destructive rather than therapeutic [74].

In addition, distraction of the joint or rest or both, applied alone, with no follow up or concurrent to modify any abnormal hip joint mechanics, or persistent joint inflammation, along with possible central factors that heighten pain-that often go undiagnosed and untreated, such as depression-can predictably foster additional degenerative joint changes, and continued pain. On the other hand, knowing which sources of pain predominate, and the possible key pain pathways that may be dysfunctional or implicated in a particular case may help to provide for more targeted interventions to counter hip joint pain and degeneration and its spread to other joints. While these ideas must clearly be subjected to more research because norms as well as sites of possible dysfunction are difficult to establish, the use of a "pain map" that is specific to a particular client, plus a careful physical exam, can serve to help both the clinician to map out the possible pain extent more clearly, along with the most appropriate modes of remediation.

In this regard, it is clear much more effort is needed by those in the field to elaborate upon this issue, in order to be in a position to outline safe, efficacious pain relieving approaches for restoring or attenuating painful destruction of the hip joint, especially considering the prevailing disease burden, and that some apparently helpful approaches may prove more harmful than not. Indeed, the removal of pain alone-may not alter the abnormalities producing hip joint dysfunction, for example, pain of metabolic origin [76], and local injections and other remedies that do not carefully consider anatomical and physiological factors may fail to treat pain sources effectively [13]. Post surgical pain at the hip 
also requires careful individualized attention as observed by Sjoveian and Leegard [77] and Greimel et al. [78], and may be predicted by the degree of presurgical pain [78]. In addition, because comorbid diseases can produce pain in their own right, these, if present, should be specifically targeted [36] [79], as should prevailing sleep disturbances [80], as well as gait disturbances [81] that can cause pain. Alternately, proper care and treatment of chronic pain could be a way of reducing gait problems and thereby fall risk and injury possible associated increases in pain [81].

To this end, the willingness and motivation to conduct careful a differential diagnosis of the possible osteoarthritis pain sources, followed by an array of targeted and tailored muscle directed therapies, patient education, and other strategies designed to reduce excess joint stress, while improving the capacity of the joint to absorb shock, may be especially helpful [82]. A role for nutritional factors, such as vitamin D, efforts to control stress, plus the appropriate use of assistive devices, sound footwear and orthotics, as well as factors related to sleep hygiene and pain self-efficacy, should not be ignored.

\section{Discussion}

This review focused on hip joint osteoarthritis and pain as related to its innervation sources and functional associations, and the author spent many months on trying to ensure all relevant articles were read and included, as indicated. Even, in the event some articles are missing, these reviewed data sources show that pain, the symptom of most concern to the hip osteoarthritis patient, is clearly highly complicated to unravel, and although highly common, is not uniform either in its distribution or nature among patients with hip joint osteoarthritis, even at the end stages of the disease. There is also very little evidence of a direct or linear association between the intensity of the pain experience and the degree of structural damage of the joint, and the presence of unrelieved pain appears to lower the pain threshold and potentiate a state of pain sensitization. Since pain is linked to disability, even if not associated radiographically, these diverse expressions of oftentimes unrelenting pain, clearly warrant much attention, given the fact neither surgery nor pharmaceutical interventions uniformly ameliorate pain accompanying the disease to any degree.

In this respect, while this present review did not focus on source research quality, it seems hard to refute the idea that a concerted effort at the outset to identify not only the type of pain being experienced by a hip osteoarthritis patient, but also its location, frequency, and possible origins, will prove more beneficial than not. After that, and subject to careful study, carefully selected pain control or minimization strategies deemed therapeutic rather than palliative that can be applied and readily monitored, and modified as indicated are likely to prove helpful, regardless of disease stage or extent.

As outlined by Syx et al. [41], and in absence of safe and effective remedies to quell osteoarthritis hip pain, the knowledge that mechanoreceptors in the joint can be favorably stimulated, and nociceptive inputs reduced by a number of 
physical and biomechanical measures may prove helpful [83]. As well, the acknowledgment that many of the diverse sources of hip joint pain shown in Table 1 , may be traceable to remediable neurological factors and others, may be helpful [84] [85]. As well, despite a strong database of preclinical studies that purport to examine and explain osteoarthritic pain, it is concluded a more insightful conceptualization of the interrelationship between the anatomical and neurological-functions of the human hip joint nerves and their ramifications as this pertains to osteoarthritis joint pain will be immensely helpful in advancing the urgent need to improve upon less than satisfactory current hip osteoarthritis treatment outcomes. In particular, understanding the variations in that exist in hip joint innervation patterns and their distribution, and how these are independently or collectively associated with hip osteoarthritis pain, may prove of paramount importance in efforts to minimize the onset of osteoarthritis related neuropathic and/or centralized pain, as well as rest pain and insomnia. As well, a better understanding of the interactions that may exist between the key nerve endings that supply the hip joint, the presence of obesity, and hip osteoarthritis pain processes, as well as cognitive pain correlates such as depression [86] [87] is clearly desirable.

To this end, adequate screening, followed by state of the art imaging technologies, electrophysiological assays and others, as well as standardized clinical tests, and personal surveys, pain drawings or maps [73] as indicated is highly recommended [73]. After that, customized techniques aimed at normalizing hip joint biomechanics, mechanoreceptor and neuromuscular coordination, while reducing observed modifiable sources of noxious stimulation may prove of high value. Among other approaches are the possible application of protected activity principles, hip mobilization techniques as discussed by Beselga et al. [83], a combination of patient education as discussed by Poulsen et al. [73] and supervised exercise trainings as described by Juhakoski et al. [84]. As well, efforts to control body weight, foster sleep hygiene, and reduce cognitive stressors, if desirable, may be helpful. The use of narcotics or pharmacologic approaches that eliminate pain on the other hand may be counterproductive, or have no durable effect [85], especially if excess loading ensues in the face of no noxious warning signs to indicate possible excess loading, and should not be encouraged as first line pain relieving remedies. Other side effects such as possible dizziness, fatigue, and falls injuries, especially among the older patients, are additional reasons for high caution in advocating solely for pain relief, without attending to its possible origin[s]. Another is the evocation of mechanical allodynia, which is a painful response to innocuous stimuli such as joint movement, consequent to the increased sensitization of articular nociceptors to mechanical stimuli [26] that can foster the depolarization of high-threshold mechanosensitive ion channels that convert mechanical forces into pain provoking stimuli.

On the other hand, since possible causes of hip osteoarthritis pain may be largely behavioral, a carefully organized set of behavioral based interventions, may predictably assist in efforts to reduce, reverse, or minimize the extent of hip 
osteoarthritis pain and suffering in many cases without excessive reliance on surgery, as proposed by Ren et al. [52], as well as in those undergoing surgery [87]. In particular, to avert the likelihood of any ensuing peripheral and central sensitization and neuropathic pain syndromes as is being observed in this progressive disease quite frequently in recent research studies, the clinician or primary caregiver should spare no efforts in collaborating with the patient to apprise them of injurious behaviors that can exacerbate their pain. In this respect, maximizing a proactive, rather than a reactive approach to treating osteoarthritis pain, including patient education of risky treatments [88], with an emphasis on managing modifiable sources of nociceptive transmission [89] is strongly indicated.

\section{Conclusions}

Hip joint pain experienced by people suffering from osteoarthritis of one or both hips, while rarely life threatening, is a profound determinant of excess morbidity, and at times mortality, as a result of the use of some toxic pain related remedies. Notwithstanding the importance of pharmacologic and surgical interventions, their limitations remain stumbling blocks for many to a high life quality.

In this respect, and in recognition of the limited and fragmented database in this regard, it is concluded that to improve upon our understandings of the origins of hip osteoarthritis pain, future high quality well-conceived and adequately funded clinical and basic research studies that explore whether an endogenous pain modulation impairment is a significant contributor to hip osteoarthritis pain [90], along with any possible descending neural pathway dysfunction, plus the role of brain specific pain activity [75] [91] and hip joint mechanoreception [92] in this disease, topics not well studied, will be extremely helpful and are strongly encouraged.

\section{Conflicts of Interest}

The authors declare no conflicts of interest regarding the publication of this paper.

\section{References}

[1] Goldstein, D.J., Wang, O., Todd, L.E., Gitter, B.D., DeBrota, D.J. and Iyengar, S. (2000) Study of the Analgesic Effect of Lanepitant in Patients with Osteoarthritis Pain. Clinical Pharmacology and Therapy, 67, 419-426. https://doi.org/10.1067/mcp.2000.105243

[2] Seidel, M.F., Wise, B.L. and Lane, N.E. (2013) Nerve Growth Factor: An Update on the Science and Therapy. Osteoarthritis and Cartilage, 21, 1223-1228. https://doi.org/10.1016/j.joca.2013.06.004

[3] Simons, M.J., Amin, N.H., Cushner, F.D. and Scuderi, G.R. (2015) Characterization of the Neural Anatomy in the Hip Joint to Optimize Periarticular Regional Anesthesia in Total Hip Arthroplasty. Journal of Surgical Orthopedic Advances, 24, 221-224. https://doi.org/10.3113/JSOA.2015.0221 
[4] Grieve, G. (1983) The Hip. Physiotherapy, 69, 196-204.

[5] Singleton, M.C. and LeVeau, B.F. (1975) The Hip Joint: Structure, Stability and Stress. Physical Therapy, 55, 957-973. https://doi.org/10.1093/ptj/55.9.957

[6] Gardener, E. (1948) The Innervation of the Hip Joint. Anatomical Record, 101, 109-130. https://doi.org/10.1002/ar.1091010111

[7] Eitner, A., Hofmann, G.O. and Schaible, H.G. (2017) Mechanisms of Osteoarthritic Pain. Studies in Humans and Experimental Models. Frontiers in Molecular and Neuroscience, 10, 349. https://doi.org/10.3389/fnmol.2017.00349

[8] Sziver, E., Nagy, E., Preszner-Domján, A., Pósa, G., Horvath, G., Balog, A. and Tóth, K. (2016) Postural Control in Degenerative Diseases of the Hip Joint. Clinical Biomechanics, 35, 1-6. https://doi.org/10.1016/j.clinbiomech.2016.04.001

[9] Vilensky, J.A. and Cook, J.A. (1998) Neurogenic Acceleration of Osteoarthritis. Current Opinion in Rheumatology, 10, 251-255. https://doi.org/10.1097/00002281-199805000-00016

[10] Redmond, J.M., Gupta, A., Nasser, R. and Domb, B.G. (2015) The Hip-Spine Connection: Understanding Its Importance in the Treatment of Hip Pathology. Orthopedics, 38, 49-55. https://doi.org/10.3928/014774477-20150105-07

[11] Trouvin, A.P. and Perrot, S. (2018) Pain in Osteoarthritis. Implications for Optimal Management. Joint Bone and Spine, 85, 429-434.

https://doi.org/10.1016/j.jbspin.2017.08.002

[12] Dee, R. (1969) Structure and Function of Hip Joint Innervation. Annals of the Royal College of Surgery, 45, 357-374.

[13] Birnbaum, K., Prescher, A., Hessler, S. and Heller, K.D. (1997) The Sensory Innervation of the Hip Joint: An Anatomical Study. Surgery Radiology and Anatomy, 19, 371-375. https://doi.org/10.1007/BF01628504

[14] Alzaharani, A., Bali, K., Gudena, R., Railton, P., Ponjevic, D., Matyas, J.R. and Powell, J.N. (2014) The Innervation of the Human Acetabular Labrum and Hip Joint: An Anatomic Study. BMC Musculoskeletal Disorders, 15, 41. https://doi.org/10.1186/1471-2474-15-41

[15] Huang, C.H., Hou, S.M. and Yeh, L.S. (2013) The Innervation of Canine Hip Joint Capsule: An Anatomic Study. Anatomy Histology and Embryology, 42, 425-431. https://doi.org/10.1111/ahe.12033

[16] Gerhardt, M., Johnson, K., Atkinson, R., Snow, B., Shaw, C., Brown, A. and Vangsness, C.T. (2012) Characterisation and Classification of the Neural Anatomy in the Human Hip Joint. Hip International, 22, 75-81. https://doi.org/10.5301/HIP.2012.9042

[17] Shirai. C., Ohtori, S., Kishida, S., Harada, Y. and Moriya, H. (2009) The Pattern of Distribution of PGP 9.5 and TNF-Alpha Immunoreactive Sensory Nerve Fibers in the Labrum and Synovium of the Human Hip Joint. Neuroscience Letters, 450, 18-22. https://doi.org/10.1016/j.neulet.2008.11.016

[18] Haversath, M., Hanke, J., Landgraeber, S., Herten, M., Zilkens, C., Krauspe, R. and Jäger, M. (2013) The Distribution of Nociceptive Innervation in the Painful Hip: A Histological Investigation. Bone and Joint Journal, 95-B, 770-776. https://doi.org/10.1302/0301-620X.95B6.30262

[19] Kılıçarslan, K., Kılıçarslan, A., Demirkale, İ., Aytekin, M.N., Aksekili, M.A. and Uğurlu, M. (2015) Immunohistochemical Analysis of Mechanoreceptors in Transverse Acetabular Ligament and Labrum: A Prospective Analysis of 35 Cases. Acta Orthopaedica et Traumatologica Turcica, 49, 394-398. 
[20] Moraes, M.R., Cavalcante, M.L., Leite, J.A., Macedo, J.N., Sampaio, M.L., Jamacaru, V.F. and Santana, M.G. (2011) The Characteristics of the Mechanoreceptors of the Hip with Arthrosis. Journal of Orthopedic Surgery and Research, 6, 58. https://doi.org/10.1186/1749-799X-6-58

[21] Leunig, M., Beck, M., Stauffer, E., Hertel, R. and Ganz, R. (2000) Free Nerve Endings in the Ligamentum Capitis Femoris. Acta Orthopedica Scandinavica, 71, 452-454. https://doi.org/10.1080/000164700317381117

[22] Saxler, G., Löer, F., Skumavc, M., Pförtner, J. and Hanesch, U. (2007) Localization of SP- and CGRP-Immunopositive Nerve Fibers in the Hip Joint of Patients with Painful Osteoarthritis and of Patients with Painless Failed Total Hip Arthroplasties. European Journal of Pain, 11, 67-74. https://doi.org/10.1016/j.ejpain.2005.12.011

[23] Genth, B., Von Düring, M., Von Engelhardt, L.V., Ludwig, J., Teske, W. and Von Schulze-Pellengahr, C. (2012) Analysis of the Sensory Innervations of the Greater Trochanter for Improving the Treatment of Greater Trochanteric Pain Syndrome. Clinical Anatomy, 25, 1080-1086. https://doi.org/10.1002/ca.22035

[24] Rabinowicz, T. and Jacqueline, F. (1990) Pathology of the Capsular and Synovial Hip Nerves in Chronic Hip Diseases. Pathology Research Practice, 182, 283-292. https://doi.org/10.1016/S0344-0338(11)80546-7

[25] He, B.H., Christin, M., Mouchbahani-Constance, S., Davidova, A. and Sharif-Naeini, R. (2017) Mechanosensitive Ion Channels in Articular Nociceptors Drive Mechanical Allodynia in Osteoarthritis. Osteoarthritis and Cartilage, pii: S1063-4584(17)31161-5. https://doi.org/10.1016/j.joca.2017.08.012

[26] Wyke, B. (1972) Articular Neurology. Physiotherapy, 58, 94-99.

[27] Pawlak, M., Borkiewicz, P., Podgórski, T. and Schmidt, R.F. (2008) The Activity of Fine Afferent Nerve Fibres of the Rat Knee Joint and Their Modulation by Inflammatory Mediators. Ortopedia Traumatologia Rehabilitacj, 10, 63-74.

[28] Kapetanakis, S., Dermon, A., Gkantsinikoudis, N., Kommata, V., Soukakos, P. and Dermon, C.R. (2017) Acetabular Labrum of Hip Joint in Osteoarthritis: A Qualitative Original Study and Short Review of the Literature. Journal of Orthopedic Surgery (Hong Kong), 25, 2309499017734444. https://doi.org/10.1177/2309499017734444

[29] Chien, C.H., Wang, S.C. and Shenand, C.L. (1994) Innervation of the Ligament of the Femoral Head in the Formosan Rock Monkey: A Retrograde HRP Tracing and Ultrastructural Study. Journal of Anatomy, 184, 65-71.

[30] Salaffi, F., Carotti, M., Stancati, A. and Grassi, W. (2005) Health-Related Quality of Life in Older Adults with Symptomatic Hip and Knee Osteoarthritis: A Comparison with Matched Healthy Controls. Aging Clinical and Experimental Research, 17, 255-563. https://doi.org/10.1007/BF03324607

[31] Zimmermann, M. (1989) Pain Mechanisms and Mediators in Osteoarthritis. Seminars in Arthritis and Rheumatism, 18, 22-29. https://doi.org/10.1016/0049-0172(89)90012-7

[32] Nummenmaa, E., Hämäläinen, M., Moilanen, L.J., Paukkeri, E.L., Nieminen, R.M., Moilanen, T., et al. (2016) Transient Receptor Potential Ankyrin 1 (TRPA1) Is Functionally Expressed in Primary Human Osteoarthritic Chondrocytes. Arthritis Research and Therapy, 18, 185. https://doi.org/10.1186/s13075-016-1080-4

[33] Weinstein, J. (1991) Neurogenic and Nonneurogenic Pain and Inflammatory Mediators. The Orthopedic Clinics of North America, 22, 235-246.

[34] Grässel, S. and Muschter, D. (2017) Peripheral Nerve Fibers and Their Neurotransmitters in Osteoarthritis Pathology. International Journal of Molecular 
Science, 18, pii: E931. https://doi.org/10.3390/ijms18050931

[35] Buckland, A.J., Steinmetz, L., Zhou, P., Vasquez-Montes, D., Kingery, M., Stekas, N.D., et al. (2019) Spinopelvic Compensatory Mechanisms for Reduced Hip Motion (ROM) in the Setting of Hip Osteoarthritis. Spine Deformities, 7, 923-928. https://doi.org/10.1016/j.jspd.2019.03.007

[36] Calders, P. and Van Ginckel, A. (2018) Presence of Comorbidities and Prognosis of Clinical Symptoms in Knee and/or Hip Osteoarthritis: A Systematic Review and Meta-Analysis. Seminars in Arthritis and Rheumatism, 47, 805-813. https://doi.org/10.1016/j.semarthrit.2017.10.016

[37] Egloff, C., Hügle, T. and Valderrabano, V. (2012) Biomechanics and Pathomechanisms of Osteoarthritis. Swiss Medical Weekly, 142, w13583. https://doi.org/10.4414/smw.2012.13583

[38] Hunter, D.J., McDougall, J.J. and Keefe, F.J. (2008) The Symptoms of Osteoarthritis and the Genesis of Pain. Rheumatic Disease Clinics of North America, 34, 623-643. https://doi.org/10.1016/j.rdc.2008.05.004

[39] Malfait, A.M. and Schnitzer, T.J. (2013) Towards a Mechanism-Based Approach to Pain Management in Osteoarthritis. Nature Review Rheumatology, 9, 654-664. https://doi.org/10.1038/nrrheum.2013.138

[40] Marks, R. (1992) Peripheral Articular Mechanisms in Pain Production in Osteoarthritis. Australian Journal of Physiotherapy, 38, 289-298. https://doi.org/10.1016/S0004-9514(14)60572-9

[41] Syx, D., Tran, P.B., Miller, R.E. and Malfait, A.M. (2018) Peripheral Mechanisms Contributing to Osteoarthritis Pain. Current Rheumatology Reports, 20, 9. https://doi.org/10.1007/s11926-018-0716-6

[42] van Dijk, G.M., Veenhof, C., Schellevis, F., Hulsmans, H., Bakker, J.P., Arwert, H., et al. (2008) Comorbidity, Limitations in Activities and Pain in Patients with Osteoarthritis of the Hip or Knee. BMC Musculoskeletal Disorders, 9, Article No. 95. https://doi.org/10.1186/1471-2474-9-95

[43] Witt, K.L. and Vilensky, J.A. (2012) The Anatomy of Osteoarthritic Pain. Clinical Anatomy, 27, 451-454. https://doi.org/10.1002/ca.22120

[44] Xiao, J., Yu, W., Wang, X., Wang, B., Chen, J., Liu, Y. and Li, Z. (2016) Correlation between Neuropeptide Distribution, Cancellous Bone Microstructure and Joint Pain in Postmenopausal Women with Osteoarthritis and Osteoporosis. Neuropeptides, 56, 97-104. https://doi.org/10.1016/j.npep.2015.12.006

[45] Niissalo, S., Hukkanen, M., Imai, S., Törnwall, J. and Konttinen, Y.T. (2002) Neuropeptides in Experimental and Degenerative Arthritis. Annals of the New York Academy of Science, 966, 384-399. https://doi.org/10.1111/j.1749-6632.2002.tb04239.x

[46] Walsh, D.A., Mapp, P.I. and Kelly, S. (2015) Calcitonin Gene-Related Peptide in the Joint: Contributions to Pain and Inflammation. British Journal of Clinical Pharmacology, 80, 965-978. https://doi.org/10.1111/bcp.12669

[47] Dudek, A., Chrószcz, A., Janeczek, M., Sienkiewicz, W. and Kaleczyc, J. (2013) Sources of Sensory Innervation of the Hip Joint Capsule in the Rabbit-A Retrograde Tracing Study. Anatomia, Histologia, Embryologia: Journal of Veterinary Medicine Series C, 42, 403-409. https://doi.org/10.1111/ahe.12028

[48] Schmaedecke, A., Saut, J.P. and Ferrigno, C.R. (2008) A Quantitative Analysis of the Nerve Fibres of the Acetabular Periosteum of Dogs. Veterinary and Comparative Orthopaedics and Traumatology, 21, 413-417. 
https://doi.org/10.3415/VCOT-07-10-0098

[49] Rankin, J.S. and Diesem, C.D. (1976) Innervation of the Equine Hip and Stifle Joint Capsules. Journal of the American Veterinary Medical Association, 169, 614-619.

[50] Vasconcelos, D.M., Ribeiro-da-Silva, M., Mateus, A., Alves, C.J., Machado, G.C., Machado-Santos, J., et al. (2016) Immune Response and Innervation Signatures in Aseptic Hip Implant Loosening. Journal of Translational Medicine, 14, 205. https://doi.org/10.1186/s12967-016-0950-5

[51] Takeshita, M., Nakamura, J., Takahashi, K., Inoue, G., Orita, S., Miyagi, M., et al. (2012) Sensory Innervation and Inflammatory Cytokines in Hypertrophic Synovia Associated with Pain Transmission in Osteoarthritis of the Hip: A Case-Control Study. Rheumatology, 51, 1790-1795. https://doi.org/10.1093/rheumatology/kes173

[52] Ren, G., Lutz, I., Railton, P., Wiley, J.P., McAllister, J., Powell, J. and Krawetz, R.J. (2018) Serum and Synovial Fluid Cytokine Profiling in Hip Osteoarthritis: Distinct from Knee Osteoarthritis and Correlated with Pain. BMC Musculoskeletal Disorders, 19, 39. https://doi.org/10.1186/s12891-018-1955-4

[53] Rutherford, D., Buckingham, L., Moreside, J., Wong, I. and Richardson, G. (2018) Knee Motion and Muscle Activation Patterns Are Altered in Hip Osteoarthritis: The Effect of Severity on Walking Mechanics. Clinical Biomechechanics, 59, 1-7. https://doi.org/10.1016/j.clinbiomech.2018.08.001

[54] Saxler, G., Löer, F., von Knoch, M., von Knoch, F. and Hanesch, U. (2005) Localization of the Neurokinin 1 Receptor in Hip Joints of Patients with Painful Osteoarthritis. Zeitshrift fur Orthopadie und Ihre Grenzgebiete, 143, 424-430. https://doi.org/10.1055/s-2005-836832

[55] Nakajima, T., Ohtori, S., Nakamura, J., Suzuki, T., Aoki, Y., Watanabe, A., et al. (2017) Inflammatory Pain-Related Traits of Sensory DRG Neurons Innervating the Hip Joints. Journal of Orthopedic Science, 22, 325-329. https://doi.org/10.1016/j.jos.2016.12.001

[56] Rankin, A.T., Bleakley, C.M. and Cullen, M. (2015) Hip Joint Pathology as a Leading Cause of Groin Pain in the Sporting Population: A 6-Year Review of 894 Cases. American Journal of Sports Medicine, 43, 1698-1703. https://doi.org/10.1177/0363546515582031

[57] Kenny, P., O’Brien, C.P., Synnott, K. and Walsh, M.G. (1999) Damage to the Superior Gluteal Nerve after Two Different Approaches to the Hip. Journal of Bone and Joint Surgery, 81B, 979-981. https://doi.org/10.1302/0301-620X.81B6.0810979

[58] Miguel-Pérez, M., Ortiz-Sagristà, J.C., López, I., Pérez-Bellmunt, A., Llusá, M., Alex, L. and Combalia, A. (2010) How to Avoid Injuries of the Superior Gluteal Nerve. Hip International, 20, S26-S31. https://doi.org/10.5301/HIP.2010.2761

[59] Arnoldi, C.C., Linderholm, H. and Mussbichler, H. (1972) Venous Engorgement and Intraosseous Hypertension in Osteoarthritis of the Hip. Journal of Bone and Joint Surgery, 54B, 409-421. https://doi.org/10.1302/0301-620X.54B3.409

[60] Duncan, C.P. and Shim, S.S. (1977) The Autonomic Nerve Supply of Bone. Journal of Bone and Joint Surgery, 59B, 323-330. https://doi.org/10.1302/0301-620X.59B3.19482

[61] Havelin, J. and King T. (2018) Mechanisms Underlying Bone and Joint Pain. Current Osteoporosis Reports, 16, 763-771. https://doi.org/10.1007/s11914-018-0493-1

[62] O’Neill, T.W., McCabe, P.S. and McBeth, J. (2018) Update on the Epidemiology, Risk Factors and Disease Outcomes of Osteoarthritis. Best Practices in Research and Clinical Rheumatology, 32, 312-326. https://doi.org/10.1016/j.berh.2018.10.007 
[63] O'Neill, T.W. and Felson, D.T. (2018) Mechanisms of Osteoarthritis (OA) Pain. Current Osteoporosis Reports, 16, 611-616. https://doi.org/10.1007/s11914-018-0477-1

[64] Sakamoto, J., Morimoto, Y., Ishii, S., Nakano, J., Manabe, Y., Okita, M. and Tsurumoto, T. (2014) Investigation and Macroscopic Anatomical Study of Referred Pain in Patients with Hip Disease. Journal of Physical Therapy Science, 26, 203-208. https://doi.org/10.1589/jpts.26.203

[65] Pan, F. and Jones, G. (2018) Clinical Perspective on Pain and Pain Phenotypes in Osteoarthritis. Current Rheumatology Reports, 20, 79. https://doi.org/10.1007/s11926-018-0796-3

[66] French, H.P., Smart, K.M. and Doyle, F. (2017) Prevalence of Neuropathic Pain in Knee or Hip Osteoarthritis: A Systematic Review and Meta-Analysis. Seminars in Arthritis and Rheumatism, 47, 1-8. https://doi.org/10.1016/j.semarthrit.2017.02.008

[67] Miura, Y., Ohtori, S., Nakajima, T., Kishida, S., Harada, Y. and Takahashi, K. (2011) Dorsal Root Ganglion Neurons with Dichotomizing Axons Projecting to the Hip Joint and the Knee Skin in Rats: Possible Mechanism of Referred Knee Pain in Hip Joint Disease. Journal of Orthopedic Science, 16, 799-804. https://doi.org/10.1007/s00776-011-0144-1

[68] Tague, S.E. and Smith, P.G. (2014) Vitamin D Deficiency Leads to Sensory and Sympathetic Denervation of the Rat Synovium. Neuroscience, 279, 77-93. https://doi.org/10.1016/j.neuroscience.2014.08.035

[69] Olesen, A.E., Nielsen, L.M., Feddersen, S., Erlenwein, J., Petzke, F., Przemeck, M., et al. (2018) Association between Genetic Polymorphisms and Pain Sensitivity in Patients with Hip Osteoarthritis. Pain Practice, 18, 587-596. https://doi.org/10.1111/papr.12648

[70] Jahanban-Esfahlan, R., Mehrzadi, S., Reiter, R.J., Seidi, K., Majidinia, M., Baghi, H.B., et al. (2018) Melatonin in Regulation of Inflammatory Pathways in Rheumatoid Arthritis and Osteoarthritis: Involvement of Circadian Clock Genes. British Journal of Pharmacology, 175, 3230-3238. https://doi.org/10.1111/bph.13898

[71] Izumi, M., Petersen, K.K., Arendt-Nielsen, L. and Graven-Nielsen, T. (2014) Pain Referral and Regional Deep Tissue Hyperalgesia in Experimental Human Hip Pain Models. Pain, 155, 792-800. https://doi.org/10.1016/j.pain.2014.01.008

[72] Wroblewski, B.M. (1978) Pain in Osteoarthrosis of the Hip. Practitioner, 220, 140-141.

[73] Poulsen, E., Overgaard, S., Vestergaard, J.T., Christensen, H.W. and Hartvigsen, J. (2016) Pain Distribution in Primary Care Patients with Hip Osteoarthritis. Family Practice, 33, 601-606. https://doi.org/10.1093/fampra/cmw071

[74] Bhatia, A., Hoydonckx, Y., Peng, P. and Cohen, S.P. (2018) Radiofrequency Procedures to Relieve Chronic Hip Pain: An Evidence-Based Narrative Review. Regional Anesthesia and Pain Medicine, 43, 72-83. https://doi.org/10.1097/AAP.0000000000000694

[75] Ji, R.R., Berta, T. and Nedergaard, M. (2013) Glia and Pain: Is Chronic Pain a Gliopathy? Pain, 154, S10-S28. https://doi.org/10.1016/j.pain.2013.06.022

[76] Bas, S., Finckh, A., Puskas, G.J., Suva, D., Hoffmeyer, P., Gabay, C. and Lübbeke, A. (2014) Adipokines Correlate with Pain in Lower Limb Osteoarthritis: Different Associations in Hip and Knee. International Orthopedics, 38, 2577-2583. https://doi.org/10.1007/s00264-014-2416-9

[77] Sjøveian, A.K.H. and Leegaard, M. (2017) Hip and Knee Arthroplasty-Patient's 
Experiences of Pain and Rehabilitation after Discharge from Hospital. International Journal of Orthopedic Trauma and Nursing, 27, 28-35. https://doi.org/10.1016/j.ijotn.2017.07.001

[78] Greimel, F., Dittrich, G., Schwarz, T., Kaiser, M., Krieg, B., Zeman, F., et al. (2018) Course of Pain after Total Hip Arthroplasty within a Standardized Pain Management Concept: A Prospective Study Examining Influence, Correlation, and Outcome of Postoperative Pain on 103 Consecutive Patients. Archives of Orthopedic Trauma and Surgery, 138, 1639-1645. https://doi.org/10.1007/s00402-018-3014-X

[79] Alvarez, C., Cleveland, R.J., Schwartz, T.A., Renner, J.B., Murphy, L.B., Jordan, J.M., Callahan, L.F., Golightly, Y.M. and Nelson, A.E. (2020) Comorbid Conditions and the Transition among States of Hip Osteoarthritis and Symptoms in a Community-Based Study: A Multi-State Time-to-Event Model Approach. Arthritis Research and Therapy, 22, 12. https://doi.org/10.1186/s13075-020-2101-x

[80] Martinez, R., Reddy, N., Mulligan, E.P., Hynan, L.S. and Wells, J. (2019) Sleep Quality and Nocturnal Pain in Patients with Hip Osteoarthritis. Medicine (Baltimore), 98, e17464. https://doi.org/10.1097/MD.0000000000017464

[81] de Kruijf, M., Verlinden, V.J., Huygen, F.J., Hofman, A., van der Geest, J.N., Uitterlinden, A.G., et al. (2015) Chronic Joint Pain in the Lower Body Is Associated with Gait Differences Independent from Radiographic Osteoarthritis. Gait and Posture, 42, 354-359. https://doi.org/10.1016/j.gaitpost.2015.06.193

[82] Ceballos-Laita, L., Estébanez-de-Miguel, E., Martín-Nieto, G., Bueno-Gracia, E., Fortún-Agúd, M. and Jiménez-Del-Barrio, S. (2019) Effects of Non-Pharmacological Conservative Treatment on Pain, Range of Motion and Physical Function in Patients with Mild to Moderate Hip Osteoarthritis. A Systematic Review. Complementary Therapies in Medicine, 42, 214-222. https://doi.org/10.1016/j.ctim.2018.11.021

[83] Beselga, C., Neto, F., Alburquerque-Sendín, F., Hall, T. and Oliveira-Campelo, N. (2016) Immediate Effects of Hip Mobilization with Movement in Patients with Hip Osteoarthritis: A Randomised Controlled Trial. Manual Therapy, 22, 80-85. https://doi.org/10.1016/j.math.2015.10.007

[84] Juhakoski, R., Malmivaara, A., Lakka, T.A., Tenhonen, S., Hannila, M.L. and Arokoski, J.P. (2013) Determinants of Pain and Functioning in Hip Osteoarthritis-A Two-Year Prospective Study. Clinical Rehabilitation, 27, 281-287. https://doi.org/10.1177/0269215512453060

[85] Edmonds-Seal, J., Turner, A., Khodadadeh, S., Bader, D.L. and Fuller, D.J. (1982) Regional Hip Blockade in Osteoarthrosis. Effects on Pain Perception. Anaesthesia, 37, 147-151. https://doi.org/10.1111/j.1365-2044.1982.tb01055.x

[86] Parmelee, P.A., Tighe, C.A. and Dautovich, N.D. (2015) Sleep Disturbance in Osteoarthritis: Linkages with Pain, Disability, and Depressive Symptoms. Arthritis Care and Research (Hoboken), 67, 358-365. https://doi.org/10.1002/acr.22459

[87] Schwarze, M., Häuser, W., Schmutzer, G., Brähler, E., Beckmann, N.A. and Schiltenwolf, M. (2019) Obesity, Depression and Hip Pain. Musculoskeletal Care, 17, 126-132. https://doi.org/10.1002/msc. 1380

[88] Holtzman, J., Saleh, K. and Kane, R. (2002) Effect of Baseline Functional Status and Pain on Outcomes of Total Hip Arthroplasty. Journal of Bone and Joint Surgery, 84A, 1942-1948. https://doi.org/10.2106/00004623-200211000-00006

[89] Brooks, A.K. and Udoji, M.A. (2016) Interventional Techniques for Management of Pain in Older Adults. Clinics in Geriatric Medicine, 32, 773-785.

https://doi.org/10.1016/j.cger.2016.06.003 
[90] Chiu, K.W., Hash, J., Meyers, R. and Lascelles, B.D.X. (2020) The Effect of Spontaneous Osteoarthritis on Conditioned Pain Modulation in the Canine Model. Science Report, 10, 1694. https://doi.org/10.1038/s41598-020-58499-1

[91] Gram, M., Erlenwein, J., Petzke, F., Falla, D., Przemeck, M., Emons, M.I., et al. (2017) The Cortical Responses to Evoked Clinical Pain in Patients with Hip Osteoarthritis. PLoS ONE, 12, e0186400. https://doi.org/10.1371/journal.pone.0186400

[92] Tomlinson, J., Zwirner, J., Ondruschka, B., Prietzel, T. and Hammer, N. (2020) Innervation of the Hip Joint Capsular Complex: A Systematic Review of Histological and Immunohistochemical Studies and Their Clinical Implications for Contemporary Treatment Strategies in Total Hip Arthroplasty. PLoS ONE, 15, e0229128. https://doi.org/10.1371/journal.pone.0229128 